\title{
Filigrane
}

Écoutes psychanalytiques

\section{La terreur des enfants}

\section{Sophie Gilbert}

Volume 26, numéro 1, 2017

La terreur des enfants : première partie

URI : https://id.erudit.org/iderudit/1041688ar

DOI : https://doi.org/10.7202/1041688ar

Aller au sommaire du numéro

Éditeur(s)

Revue Santé mentale au Québec

ISSN

1192-1412 (imprimé)

1911-4656 (numérique)

Découvrir la revue

Citer ce document

Gilbert, S. (2017). La terreur des enfants. Filigrane, 26(1), 9-12.

https://doi.org/10.7202/1041688ar d'utilisation que vous pouvez consulter en ligne.

https://apropos.erudit.org/fr/usagers/politique-dutilisation/ 


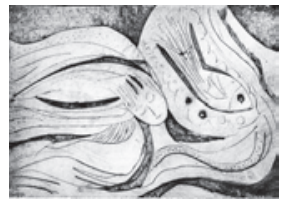

\title{
La terreur des enfants
}

\author{
Sophie Gilbert
}

A gités, opposants, agressifs, hyperactifs, etc. : comment percevons-nous aujourd'hui les enfants et, surtout, comment les comprenons-nous? Et ces enfants qui frôlent l'âge adulte, comment interpréter leur violence qui nous terrifie par l'absurdité de la mort - la leur et celle de l'autre - donnée en spectacle dans les lieux publics? Notre jeunesse est-elle en mal d'action, de cruauté? Quels enfants ont été ces jeunes adultes? Quels parents ont-ils eus? Dans quelle société ont-ils évolué?

Le clinicien est aujourd'hui interpelé sur la place publique par une violence qui le dépasse. De même que dans son bureau privé et dans l'institution, lorsqu'on lui demande de «réparer» ces enfants, ces jeunes. Des plus turbulents et opposants, à ceux qui sont carrément pressentis comme «hors contrôle », quelles réponses a-t-il à offrir?

Qui a peur de qui? Quand dans nos services de protection de l'enfance, l'on attribue les agirs des jeunes à une «menace extérieure », le «méchant» en marge de la société, et que l'on aspire à les contrôler par une simple serrure de plus ${ }^{1}$. Si cet exemple est éloquent, c'est que dans cette histoire comme dans tant d'autres problématiques juvéniles, chacun accuse l'autre, l'extérieur, le différent. Qui est responsable? Le père ou la mère? L'école ou le parent? L'institution ou les gangs de délinquants? Mais dans d'autres situations, c'est bien l'autre sous toutes ses formes que l'on pointera du doigt: l'autre culture, l'autre religion, l'autre couleur de peau, l'autre pays... tout ce qui nous semble étranger et par le fait même, hors notre pouvoir.

D'un point de vue psychanalytique, si nous pouvons sans doute discuter longuement de ce regard porté sur la différence (pensons à l'inquiétante étrangeté ou au narcissisme des petites différences), passé le choc de l'horreur, nous pouvons du moins réfléchir à cette violence en tant qu'inhérente au sujet humain. Revenir à cette notion de pulsion comme incontournable, à réfréner, sans doute... mais aussi à sublimer, à exprimer autrement ${ }^{2}$.

Quelles pulsions habitent nos enfants? Que veulent-ils exprimer? Pourquoi les mots sont-ils si souvent insuffisants et en quoi ne peuvent-ils 
désormais traduire les «maux»? Maurice Berger nous parlait déjà, il y a une dizaine d'années, des «enfants barbares»... entendu par cela que ceux-ci risquaient de s'écarter, de par leurs actes, de la norme qui assujettit l' « humanité». Loin de poser un jugement sur ces enfants - y a-t-il plus grand défenseur de leur cause que Maurice Berger? - il rédigeait ce livre (et tant d'autres qui ont précédé et suivi), comme un appel à la réflexion, comme une remise en question de tout un chacun.

En référence à Freud, les penseurs psychanalystes ont depuis longtemps compris la violence humaine en termes pour le moins subversifs. S'il y a malaise dans la (ou serait-ce plutôt « de par la») civilisation, c'est justement à force de réprimer ce qui en nous pourrait friser la barbarie, si quelque chose du cadre du social ne peut être intégré psychiquement, porté depuis la naissance par l'autre-semblable, l'autre bienveillant.

En ce sens, peut-on tout pathologiser, même les enfants qui en très bas âge expriment leur détresse en actes? Peut-on se passer de l'environnement familial, social et culturel pour expliquer les agirs des enfants, des ados, des jeunes? Osons poser la question de manière plus radicale: notre culture, celle que nous transmettons, aime-t-elle les enfants?

Interroger la violence de la jeunesse, la cruauté à laquelle nous sensibilisent de plus en plus les médias, c'est d'emblée aborder la question du cadre dans lequel ces jeunes évoluent. Si trop souvent, l'on tend à distinguer «le nôtre» du «leur», parlant des jeunes américains qui ont accès aux armes à feu, ou alors, des jeunes intégristes et de leur appui sur une religion dont les fondements nous échappent... bref, si l'on cherche ainsi à se distinguer, c'est que fondamentalement, sans doute, nous ressentons cruellement cette communauté - si ce n'est de pensée, une communauté d'être - dans la dérive actuelle. Du reste, afin de soutenir la réflexion sur les aléas de la communauté humaine au $\mathrm{xxI}^{\mathrm{e}}$ siècle, nous ne pouvons faire l'économie de la remise en cause du «vivre-ensemble» à l'occidentale.

Comment expliquer tant de problèmes, de diagnostics chez nos jeunes, nos enfants, surprotégés physiquement de la prime enfance (voir les mécanismes mis en place dans les maisons pour ne pas qu'ils se blessent, qu'ils ouvrent les armoires, qu'ils sortent dehors à notre insu, etc.) à l'adolescence, incluant les nombreux interdits qui encadrent désormais les cours d'école (jusqu'au détecteur de métal dans certaines écoles secondaires)? Si ce sont des cas isolés qui s'en prennent violemment à leur pair jugé marginal, ils sont bien plus nombreux ceux qui vivent sur la médication, dans un calme, voire une inertie artificielle... 
Qu'en est-il de cette pulsion que l'on cherche à contenir par tous les moyens - extérieurs, s'entend? Que cherchent ces enfants qui provoquent, qui bougent trop et qui souffrent du mal du siècle: ce «déficit» de l'attention? Seraient-ils justement trop attentifs au moindre mouvement extérieur afin d'échapper aux turbulences de leur monde interne - qui ne trouvent ni preneurs ni «entendeurs»?

Ces petits êtres, s'ils sont "pervers polymorphes», sont en attente... Est-ce que nos réponses actuelles sont encore adéquates? Pertinentes? Rassurantes? Sommes-nous dépassés par l'évolution si ce n'est chaotique, pour le moins accélérée de nos sociétés? Par des moyens technologiques, par une pensée (plus ou moins aboutie) qui se partage plus vite que l'éclair, par des images qui nous bombardent et font de nous les témoins instantanés des plus beaux accomplissements humains comme des plus barbares? Une technologie qui fait de nous des adultes débordés, en déficit de pensée et d'attention?

De quel ordre est le manque chez ces jeunes, ces "néo-mercenaires» qui s'allient à une Cause - aussi étrangère puisse-t-elle nous apparaître? Tout porte à croire que la quête de limites et d'idéaux constitue le pendant de l'absence de ceux-ci, dans un monde où curieusement, l'on tend à traduire liberté et égalité en une absence de contrainte... terrifiante! Alain Ehrenberg en a discuté en termes de dépression il y a déjà plusieurs années, mais ne serait-ce pas d'abord par la référence aux angoisses les plus primitives que l'on pourrait aborder cette actuelle et bouleversante «figuration » du manque?

Qui a peur de qui, ce qui revient à dire: qu'est-ce qui des agirs, de la violence actuelle que portent les enfants reflète justement cette impossibilité d'exprimer non pas la pulsion, mais la peur d'être dépassé par celle-ci? La recherche de contenance, la recherche de pare-excitation? Mais aussi, sans doute, la quête incessante, aux fondements du sujet humain, d'un simple sens à sa vie, une direction imposée non seulement par des balises, mais par un avenir attrayant. Dompter l'angoisse de la projection de soi dans le futur par un agir bien réel et conjugué au présent, pourrait bien être l'aboutissement d'un effacement, aux plans imaginaire et symbolique, de la destinée.

La parole est aux cliniciens...

Notamment ceux qui travaillent auprès de ces enfants, ces jeunes en très grande souffrance psychique... mais aussi, ceux qui reçoivent les parents en quête de réponses par rapport à ces enfants et ces jeunes qui trop souvent les désarçonnent. Finalement, à tous ceux qui sont interpelés par ce climat 
d'instabilité actuelle, dans lequel une certaine jeunesse se révolte, s'exprime, curieusement d'une façon très solitaire et destructrice, dans une quête - ou serait-ce un message - qui ne peut que nous interroger, comme cliniciens, comme citoyens.

Si les psychanalystes se sont exprimés largement sur la médication des enfants et ses dérives, peu se sont fait entendre à propos de la «terreur des enfants » : celle que l'on ressent tout un chacun lorsque confronté à l'horreur d'un enfant qui porte atteinte à sa vie ou à celle de ses pairs, celle du parent ou des proches de l'enfant qui donne à voir sa souffrance en acte, mais aussi et surtout, celle que portent ces enfants et ces jeunes angoissés, terrorisés, dans « un monde sans limite» (tel que formulé par Jean-Pierre Lebrun).

Sophie Gilbert

gilbert.sophie@uqam.ca

\section{Notes}

1. Nous faisons ici allusion à un événement très médiatisé au début 2016, dans la région de Montréal, où des jeunes filles ayant fugué des services de protection de l'enfance ont suscité la remise en question notamment du verrouillage des portes, en lien avec l'influence marquée des gangs de rue sur la propension des jeunes à fuir les Centres jeunesse.

2. À noter qu'ici, loin de nous l'idée d'opposer de nouveau la psychanalyse freudienne et ses évolutions européennes à une psychanalyse américaine (Ego psychology et écoles culturalistes). La culture demeure un élément central de l'argument que nous proposons, mais dans une perspective différente de celle, ici contestée, de l'«autre» culture. 